\title{
Effectiveness of added natural antioxidants in sunflower oil
}

\author{
By Amalia A. Carelli*, Indira C. Franco and Guillermo H. Crapiste \\ PLAPIQUI (UNS-CONICET). \\ La Carrindanga, km. 7, C.C. 717, 8000 Bahía Blanca, Argentina. \\ [Teléfono: (54-291) 4861700; Fax: (54-291) 4861600; e-mail: acarelli@plapiqui.edu.ar]
}

\section{RESUMEN}

\section{Efectividad de antioxidantes naturales adicionados a} aceite de girasol..

Se investigó la actividad antioxidante de $\propto$-tocoferol, $\delta$-tocoferol, ácido cítrico y palmitato de ascorbilo en aceite de girasol con su conteniendo natural de tocoferol. La efectividad de los mismos fue analizada a través de la medida de la estabilidad oxidativa en Rancimat y el seguimiento de la oxidación con el almacenamiento a diferentes temperaturas. Las muestras extraídas periódicamente de la estufa fueron sometidas a los siguientes análisis: índice de peróxidos, valor de $\mathrm{p}$-anisidina, contenido y distribución de compuestos polares y contenido residual de tocoferol natural. La efectividad de cada antioxidante resultó fuertemente dependiente de la temperatura y método de ensayo. Mientras el ácido ascórbico resultó ser el antioxidante más efectivo según el índice de estabilidad oxidativa medido en el equipo Rancimat, el $\delta$-tocoferol fue el antioxidante más efectivo en las experiencias de almacenamiento.

PALABRAS-CLAVE: Aceite de girasol - Antioxidantes naturales - Autooxidación - Compuestos polares.

\section{SUMMARY}

Effectiveness of added natural antioxidants in sunflower oil.

The antioxidant activity of $\propto$ - and $\delta$-tocopherol, citric acid, ascorbic acid and ascorbyl palmitate was investigated in sunflower oil containing naturally occurring tocopherol. The effectiveness of natural antioxidants in sunflower oil was monitored by the accelerated oxidative stability test Rancimat and oxidation development during storage under different conditions. Samples in storage experiments were periodically removed and analyzed for peroxide value, $\mathrm{p}$-anisidine value, total content and distribution of polar compounds, and residual naturally occurring tocopherol. The effectiveness of each antioxidant was strongly dependent on temperature and the testing method. While ascorbic acid appears to be the most effective antioxidant according to the Rancimat oxidative stability index, $\delta$-tocopherol shows improved performance when considering storage experiments.

KEY-WORDS: Autooxidation - Natural antioxidants - Polar compounds - Sunflower oil.

\section{INTRODUCTION}

The development of oxidative rancidity or autoxidation is the decisive factor affecting storage life and the use of edible oils and fats in food. Autoxidation of lipids is a natural process that occurs between molecular oxygen and unsaturated fatty acids through a free-radical chain mechanism that involves the formation of fat free radicals, peroxide free radicals and hydroperoxides. The hydroperoxides are very unstable and decompose to form secondary reaction products, such as aldehydes, ketones, alcohols and acids, which cause off-odors and off-flavors, and affect the quality of the oil. Oxidative stability and the deterioration of oils depend on the initial composition, concentration of minor compounds with antioxidant or prooxidant characteristics and storage conditions such as temperature, light, oxygen availability and type of recipient.

Antioxidants are compounds that inhibit or interfere with the oxidative process and are widely used to delay lipid oxidation. Nowadays, the addition of natural antioxidants in edible oils and fats is being suggested, since the safety of synthetic antioxidants has been questioned. Antioxidants are classified, according to their action, into primary or chain-breaking and secondary or preventive. Primary antioxidants can react with peroxyl radicals before they do so with further unsaturated lipid molecules and convert them into more stable products; tocopherols are included in this category. Secondary antioxidants act by other processes such as binding metal ions, scavenging oxygen, decomposing hydroperoxides to nonradical products, absorbing UV radiation, and deactivating singlet oxygen (Jadhav et al., 1996). Common secondary antioxidants are carotenoids, citric acid, ascorbic acid and ascorbyl palmitate among others. The combination of two antioxidants, both primaries or a primary and a secondary, can result in a synergistic effect. Besides, some antioxidants can be recycled by others; for instance, ascorbic acid is capable of regenerating $\alpha$-tocopherol from its radicals or oxidation products (Niki, 1996; Kamal-Eldin and Appelqvist, 1996; St. Angelo, 1996; Frankel, 1996). In addition, some antioxidants can have more than one mechanism of action. Research has been conducted to find out the antioxidant properties and to better understand the mechanism of oxidation and antioxidant action in lipids (Frankel, 1996; Kamal-Eldin and Appelqvist, 1996; Niki, 1996; St Angelo, 1996; Frankel, 1998; Crapiste et al., 1999; 
Yanishlieva et al., 2002). The antioxidative efficacy of antioxidants is affected by temperature, liquid composition, physical state (bulk oil phase or emulsion), and antioxidant concentration, among others (Kamal-Eldin and Appelqvist, 1996; White and Xing, 1997; Carelli et al., 1998). For this reason, controversial findings of their effects can be mainly attributed to the large differences in the substrate considered, antioxidant concentration, and testing conditions. Most of these studies have been carried out using purified oils or triacylglycerols, but scare information exists about the natural antioxidant effectiveness in oils containing endogenous minor components. It has been claimed that the addition of tocopherols or other antioxidants to most polyunsaturated oils is inefficient, because the natural content of the antioxidants in these oils is almost optimal (Yanishlieva and Marinova, 2001).

Besides, the methodology used to evaluate antioxidants and oxidative stability must be carefully interpreted depending on the conditions of oxidation and the analytical method used to determine the extent and end point of oxidation (Frankel, 1993). Nowadays, a methodology based on a combination of adsorption and size exclusion chromatography has been applied to study the alteration of lipids, enabling the joint evaluation of primary and secondary compounds (Márquez-Ruiz and Dobarganes, 1997; Carelli et al., 1998; Crapiste et al., 1999; Márquez-Ruiz et al., 2000).

The main objective of this work is to study the effectiveness of natural antioxidants in refined sunflower oil, comparing the accelerated oxidative stability test with oxidation measured under different storage conditions.

\section{EXPERIMENTAL PROCEDURES}

\subsection{Materials}

A refined sunflower oil without the addition of any preservatives was supplied by a local factory. L-ascorbic acid 6-palmitate (95\%), L-ascorbic acid $(99 \%)$ and citric acid $(99.5 \%)$ were purchased from Aldrich Chemical Company (Milwaukee, WI). In addition, $\alpha$-tocopherol (95\%) and $\delta$-tocopherol (90\%) were supplied by Sigma Chemical Company (St. Louis, MO). Concentrated solutions of antioxidants in sunflower oil (2000 ppm) were prepared; $\alpha$-tocopherol and $\delta$-tocopherol were added directly to the oil and gently stirred for several minutes; but citric acid, ascorbic acid and ascorbyl palmitate were added to the oil as acetone solutions and evaporated to dryness under nitrogen during stirring. Sunflower oil samples with different concentrations of antioxidants (0-800 ppm) were prepared from the concentrated solutions.

\subsection{Storage tests}

Oil samples treated with $100 \mathrm{ppm}$ of citric acid, ascorbyl palmitate, $\alpha$-tocopherol, $\delta$-tocopherol and ascorbic acid were stored at $30 \pm 1^{\circ} \mathrm{C}$ for 35 days, at $68 \pm 1^{\circ} \mathrm{C}$ for 23 days and at $130 \pm 1^{\circ} \mathrm{C}$ for 48 hours. Experiments at 30 and $68{ }^{\circ} \mathrm{C}$ were carried out in standard laboratory ovens; the samples kept in 100$\mathrm{mL}$ caramel-colored open glass bottles of $4 \mathrm{~cm}$ i.d. Experiments at $130{ }^{\circ} \mathrm{C}$ were performed in the Rancimat heating block using the equipment vessels. The ratio oil surface exposed area to oil volume was approximately 0.2 .

In every experiment an oil sample without the addition of an antioxidant was employed as control. Samples with the same treatment were prepared in duplicate in order to obtain two independent measurements for each time and condition. Samples were withdrawn periodically from the oven and were stored at $5{ }^{\circ} \mathrm{C}$ under nitrogen atmosphere for further analysis.

\subsection{Analytical methods}

Standard methods. Standard IUPAC (1992) and AOCS (1993) official methods were used to determine acidity or free fatty acids (FFA) (IUPAC 2.201), peroxide value (PV) (AOCS Cd 8-53), p-anisidine value (AV) (AOCS Cd 18-90). The fatty acid composition was determined by gas chromatography of the methyl esters according to IUPAC 2.301-2.302 methods. The oxidative stability index, represented as induction time in hours, was measured with a Metrohm 679 Rancimat (Metrohm, Herisau, Switzerland), at $98^{\circ} \mathrm{C}, 68^{\circ} \mathrm{C}$ and $20 \mathrm{~L} / \mathrm{h}$ airflow. Trace metals (iron and copper) were measured by flame atomic absorption with a GBC 902 Atomic Absorption Spectrometer (GBC Scientific Equipment, Victoria, Australia).

Tocopherols. The content of naturally occurring tocopherol was measured by high-performance liquid chromatography (HPLC) using the AOCS Ce 8-89 method (1993). A Varian Vista 5500 HPLC system with fluorescence detector and a LiChrosorb Si-60 (250 x $4 \mathrm{~mm}, 5 \mathrm{~m}$ particle size) column (Merck, Darmstadt, Germany) were used.

Polar compounds. Polar compounds (PC) were obtained by solid-phase extraction (SPE) using Sep-Pack silica cartridges, subsequently separated by high performance size-exclusion chromatography and quantified through the internal standard method according to Márquez-Ruiz et al. (1996). For the SPE step, $1 \mathrm{~g}$ silica gel SPE cartridges (J.T. Baker Inc., Phillipsburg, NJ) were used. Efficiency of the separation of non-polar and polar fractions by SPE was checked by thin layer chromatography according to AOCS method Cd 20-91 (1993). A Waters HPLC, two 500 and $100 \AA \mathrm{PL}$ gel $(\mathrm{L}=30 \mathrm{~cm}$, d.i. $=7.5 \mathrm{~mm}$, 
particle size $=5 \mu \mathrm{m}$ ) (Polymer Laboratories Inc., Amherst, MA) columns connected in series, a refractive index detector (Varian RI-3, Sensibility 1x10-6), tetrahydrofuran as mobile phase at 1 $\mathrm{mL} / \mathrm{min}$ (10 $\mu \mathrm{l}$ injection), and a Millenium 2010 Chromatography Manager (Millipore Corporation, Milford, MA) were used in the HPSEC analysis.

\subsection{Statistical analysis}

The average values of two independent determinations are reported in tables. The mean values and their error bars of two independent experiments are represented in figures. Polar compounds were analyzed in triplicate $(n=3)$. Differences in polar compounds between samples were assessed with Student's test, with probability values of $5 \%$ being statistically different.

\section{RESULTS AND DISCUSSION}

The initial characteristics of the refined sunflower oil used in this study are shown in Table I. Its anti- and prooxidant minor components were not eliminated in order to obtain results with industrial applications. The compositional information is essential because of the major and minor oil components' influence on the oxidative process. It is known that the rates and pathways of lipid peroxidation are affected by other chemical species in the reaction medium as well as by the physical conditions of the reaction (Kamal-Eldin and Appelqvist, 1996). The level of naturally occurring tocopherols (about 700 ppm) confers intrinsic protection to the oil.

A comparison of antioxidant performance as measured by the oxidative stability index (OSI) test is shown in Figure I. The stability of oils treated with ascorbic acid (AA) increased rapidly as the antioxidant concentration augmented. The stability of oils treated with ascorbyl palmitate (AP) increased significantly up to $400 \mathrm{ppm}$, although to a lesser extent in comparison with ascorbic acid, and slightly from 400 to $800 \mathrm{ppm}$. The ascorbic acid has the inconvenience of being oil-insoluble, but not its esters. Since the metabolism breakdown of ascorbyl palmitate yields ascorbic acid and palmitic acid, both normal metabolites, it is considered together with the ascorbic acid as a substance which has no restrictions on usage levels (Giese, 1996).

The absence of linearity in the dependencies of OSI for sunflower oil on the concentration of ascorbic acid and ascorbyl palmitate proves that these antioxidants are consumed not only in chain termination reactions but also in one or more side reactions, causing the decrease in their relative effectiveness with rising concentrations (Yanishlieva and Marinova, 1992). These antioxidants can act as synergists with tocopherols by converting oxidized tocopherol back to the reduced form. The multiple effects of ascorbic acid and ascorbyl palmitate include hydrogen donation to regenerate the antioxidant, metal inactivation to reduce the rate of initiation by metals, hydroperoxide reduction to produce stable alcohols by non-radical processes, and oxygen scavenging (Frankel, 1996).

The OSI values of the oil treated with $\delta$-tocopherol (DT) raised linearly with the amount of antioxidant. This linearity could indicate that DT does not participate in side reactions during accelerated oxidation at $98^{\circ} \mathrm{C}$, being the consumption rate of this antioxidant practically independent of its concentration under these experimental conditions (Yanishlieva and Marinova, 1992).

The remaining naturally occurring antioxidants did not exhibit significant changes, especially in the case of citric acid. This seems reasonable since the $\alpha$-tocopherol is naturally present in the oil and citric acid is mainly a chelating agent. Citric acid is a useful chelating ingredient especially when pro-oxidative metal ions such as iron and copper are present (Kamal-Eldin and Appelqvist, 1996; Giese, 1996). The quantity of those metals in the oil employed for our tests was relatively low. Tocopherols function as antioxidants by serving as free-radical terminators and by scavenging singlet oxygen molecules (St. Angelo, 1996). When relative tocopherols-antioxidant properties were compared in oils the following order $\delta>\gamma \approx \beta>\alpha$ was reported in spite of the fact that a simple structure comparison would suggest the inverse order (Kamal-Eldin and Appelqvist, 1996). This difference might be due to the fact that tocopherols and/or their radicals often undergo side reactions (reactions other than those with peroxyl radicals), which may be prooxidative, the $\alpha$-tocopherol being more disposed to this (Kamal-Eldin and

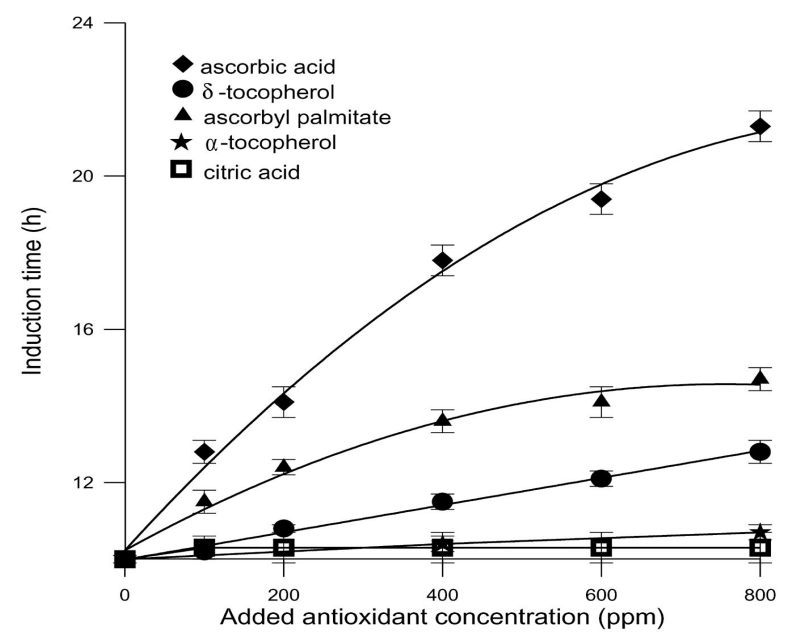

Figure 1

Rancimat oxidative stability index at $98^{\circ} \mathrm{C}$ of sunflower oil with different antioxidant treatments. 
Table I

General Characteristics of Sunflower Oil

\begin{tabular}{|c|c|}
\hline Analytical determination & \\
\hline Free fatty acids ( $\%$ oleic acid) & 0.16 \\
\hline Peroxide value (meq/kg) & 2.7 \\
\hline p-Anisidine value & 2.7 \\
\hline Oxidative stability ( $\mathrm{h}$ at $98^{\circ} \mathrm{C}$ ) & 10.0 \\
\hline \multicolumn{2}{|l|}{ Fatty acids (\%) } \\
\hline $\mathrm{C}_{16: 0}$ & 6.58 \\
\hline $\mathrm{C}_{18: 0}$ & 3.79 \\
\hline $\mathrm{C}_{18: 1}$ & 19.7 \\
\hline $\mathrm{C}_{18: 2}$ & 68.4 \\
\hline $\mathrm{C}_{18: 3}$ & 0.22 \\
\hline $\mathrm{C}_{20: 0}$ & 0.28 \\
\hline $\mathrm{C}_{22: 0}$ & 0.75 \\
\hline $\mathrm{C}_{24: 0}$ & 0.20 \\
\hline Polar Compounds (wt\%) & 7.1 \\
\hline Triglyceride polymers (\%) & 3 \\
\hline Triglyceride dimers (\%) & 26 \\
\hline Oxidized triglyceride monomers (\%) & 34 \\
\hline Diglycerids (\%) & 29 \\
\hline Free fatty acids (\%) & 8 \\
\hline Tocopherols (mg/kg) & $\alpha: 670 ; \beta: 22 ; \gamma: 20$ \\
\hline Metal content (ppm) & Fe:3.2; Cu:0.3 \\
\hline
\end{tabular}

All data reported are arithmetic means of duplicate or triplicate determinations.

Appelqvist, 1996). The tocopherol concentration is an important factor that influences tocopherol antioxidant activity in bulk oils. Studies in purified triacylglycerols obtained from sunflower oil showed that $\alpha$-tocopherol antioxidant activity is greatest at lower concentrations (<700 ppm) and loses efficacy at higher concentrations due to its participation in side reactions (Yanishlieva et al. 2002). Since the content of natural occurring $\alpha$-tocopherol in the oil used is near this limit concentration, the addition of $\alpha$-tocopherol to the oil might be inefficient, explaining the poor behavior obtained with samples treated with $\alpha$-tocopherol.

To compare the effectiveness of antioxidants a protection factor $(F)$ defined as the ratio between the
OSI induction time for the sample treated with antioxidant and the control sample $(\mathrm{F}=\mathrm{OSI} / \mathrm{OSI})_{0}$ was used. The protection factors for ascorbic acid, ascorbyl palmitate and $\delta$-tocopherol as a function of antioxidant concentration (ppm) were correlated by using least square regression to obtain:

$$
\begin{gathered}
\mathrm{F}_{\mathrm{AA}}=1.02+2.28 \times 10^{-3} \mathrm{ppm}-1.15 \times 10^{-6} \mathrm{ppm}^{2}, \mathrm{r}^{2}=0.994 \\
\mathrm{~F}_{\mathrm{AP}}=1.02+1.152 \times 10^{-3} \mathrm{ppm}-7.62 \times 10^{-7} \mathrm{ppm}^{2}, \mathrm{r}^{2}=0.985 \\
\mathrm{~F}_{\mathrm{DT}}=0.998+3.56 \times 10^{-4} \mathrm{ppm}, \mathrm{r}^{2}=0.994
\end{gathered}
$$

The natural antioxidant performance in sunflower oil measured by the OSI test can be compared with 
Table II

Deterioration analysis on samples treated with $100 \mathrm{ppm}$ of each antioxidant and stored at different temperatures

\begin{tabular}{|c|c|c|c|c|c|c|c|c|c|c|}
\hline \multirow[t]{2}{*}{ Test } & \multirow{2}{*}{$\begin{array}{l}\text { TR } \\
\text { (\%) }\end{array}$} & \multirow{2}{*}{$\begin{array}{c}\mathrm{PV} \\
\mathrm{meq} / \mathrm{kg}\end{array}$} & \multirow[t]{2}{*}{ AV } & \multicolumn{2}{|c|}{ PC } & \multicolumn{5}{|c|}{ Polar compound distribution (wt \%) } \\
\hline & & & & (wt\%) & CV(\%) & TGP & TGD & ОTG & DG & FFA \\
\hline \multicolumn{11}{|c|}{35 days at $30^{\circ} \mathrm{C}$} \\
\hline Control & 72 & 84 & 2.84 & 12.9 & 2.3 & 0.3 & 1.6 & 7.8 & 2.5 & 0.7 \\
\hline CA & 69 & 79 & 2.89 & 15.3 & 2.6 & 0.3 & 2.9 & 9.0 & 2.4 & 0.7 \\
\hline AP & 73 & 87 & 2.72 & $7.6^{\mathrm{a}}$ & 3.9 & 0.2 & 1.2 & 3.7 & 2.0 & 0.5 \\
\hline DT & 68 & 81 & 2.80 & $8.0^{\mathrm{a}}$ & 5.0 & 0.2 & 1.0 & 3.8 & 2.4 & 0.6 \\
\hline$A A$ & 75 & 85 & 2.76 & 15.3 & 3.2 & 0.4 & 3.4 & 8.1 & 2.6 & 0.8 \\
\hline \multicolumn{11}{|c|}{23 days at $68^{\circ} \mathrm{C}$} \\
\hline Control & 2 & 108 & 11.7 & 21.9 & 5.5 & 0.5 & 4.1 & 14.5 & 2.2 & 0.6 \\
\hline $\mathrm{CA}$ & 8 & 99 & 11.0 & $18.6^{\mathrm{a}}$ & 4.8 & 0.3 & 3.6 & 12.6 & 1.6 & 0.5 \\
\hline AP & 7 & 77 & 11.1 & 20.8 & 8.5 & 0.4 & 4.6 & 13.5 & 1.8 & 0.5 \\
\hline DT & 19 & 61 & 11.1 & $15.3^{\mathrm{a}}$ & 2.6 & 0.3 & 3.1 & 9.9 & 1.5 & 0.5 \\
\hline$A A$ & 8 & 80 & 10.4 & $17.2^{a}$ & 2.3 & 0.3 & 3.6 & 11.2 & 1.7 & 0.4 \\
\hline \multicolumn{11}{|c|}{24 hours at $130^{\circ} \mathrm{C}$} \\
\hline Control & 20 & 33 & 45 & 22.5 & 4.0 & 1.3 & 9.3 & 9.7 & 1.8 & 0.4 \\
\hline CA & 18 & 41 & 46 & 26.3 & 3.8 & 1.8 & 10.8 & 11.1 & 2.1 & 0.5 \\
\hline AP & 24 & 21 & 30 & $19.5^{\mathrm{a}}$ & 4.6 & 0.7 & 7.8 & 8.4 & 2.1 & 0.5 \\
\hline DT & 16 & 32 & 39 & $17.3^{\mathrm{a}}$ & 2.3 & 0.9 & 5.7 & 8.5 & 1.7 & 0.5 \\
\hline$A A$ & 1 & 44 & 60 & 31.7 & 6.6 & 2.8 & 14.5 & 11.7 & 2.0 & 0.7 \\
\hline
\end{tabular}

${ }^{a}$ Samples that show an antioxidant effect with respect to control $(n=3 ; P<0.05)$

Abbreviations: $\mathrm{CA}=$ citric acid, $\mathrm{AP}=$ ascorbyl palmitate $\mathrm{DT}=\delta$-tocopherol, $\mathrm{AA}=$ ascorbic acid, $\mathrm{TR}=$ tocopherol residual, $\mathrm{PV}=$ peroxide value, $\mathrm{AV}=$ anisidine value, $\mathrm{PC}=$ total polar compounds, $\mathrm{CV}=$ coefficient of variation, $\mathrm{TGP}=$ triglyceride polymers, TGD = triglyceride dimers, OTG = oxidized triglycerides, DG = diglycerides, FFA = free fatty acids.

the experimental results obtained for synthetic antioxidants in a previous report (Carelli et al., 1998). The antioxidative activity of $\delta$-tocopherol is comparable to that of butylated hydroxitoluene (BHT). Ascorbic acid and ascorbyl palmitate were much less potent than tertiary butylhydroquinone (TBHQ) and showed a performance intermediate between propyl gallate (PG) and BHT. Thus the same protection factor as that obtained with $200 \mathrm{ppm}$ BHT $(F=1.11)$ can be achieved by adding $40 \mathrm{ppm} \mathrm{AA}, 61$ ppm AP or $315 \mathrm{ppm}$ DT. In the same way approximately $410 \mathrm{ppm} \mathrm{AA}$ or $830 \mathrm{ppm} \mathrm{AP}$ are equivalent to $100 \mathrm{ppm} P \mathrm{PG}(\mathrm{F}=1.76)$. Finally, a similar perfomance to $50 \mathrm{ppm}$ TBHQ $(F=1.98)$ is obtained with 600 ppm AA. Natural antioxidants present the advantage of having no restriction on usage levels, while the use of $B H T, P G$ and $T B H Q$ is restricted to permitted levels, usually a maximum total antioxidant content of $200 \mathrm{ppm}$ (Giese, 1996).

The deterioration indexes employed to analyze experimental results from storage experiments are the peroxide value (PV), the $p$-anisidine value (AV), and the total content and distribution of polar compounds. The peroxide value (PV) is a common indicator of lipid oxidation, but its use is limited to the early stages of oxidation. This index accounts for hydroperoxides, labile intermediate compounds that decompose into several secondary oxidation 
products. Secondary changes can be measured by $\mathrm{p}$-anisidine value (AV), an indicator of the aldehyde content (mainly as 2-alkenals and 2,4-dienals). The origin, grade and evolution of deterioration can be evaluated from the polar compound determination. The oxidized triglyceride monomers (OTG) content is an indicator of oxidative alteration; the content of diglycerides (DG) and free fatty acids (FFA) is related to hydrolytic alteration, and polymeric compounds as triglyceride dimers (TGD) and triglyceride polymers (TGP) are useful to assess thermal alteration. Quantification of oxidized triglyceride monomers and dimers has been reported as a good measurement of early and advanced stages of oxidation, since it provides a direct measurement of primary and secondary oxidation products (Márquez-Ruiz and Dobarganes, 1997).

Experimental results after 35 days of storage at $30^{\circ} \mathrm{C}, 23$ days at $68^{\circ} \mathrm{C}$ and 1 day of heating at $130^{\circ} \mathrm{C}$ are presented in Table II. The reproducibility from the mean of two independent measures expressed by the coefficient of variation were in the ranges $0.2-13 \%$ for tocopherol residual (TR), $0.1-5.3 \%$ for $\mathrm{PV}$, and $0.1-4.7 \%$ for AV. The polar compound determination gave a coefficient of variation of $2-8.5 \%$ from the mean of three determinations.

PV increased rapidly and AV remained practically constant during storage at $30{ }^{\circ} \mathrm{C}$. Differences in TR, $\mathrm{PV}$ and $\mathrm{AV}$ in relation to the control sample were not observed at this temperature. However, analysis of polar compounds showed an antioxidant effect for AP and DT $(\mathrm{P}<0.05)$.

Some differences in TR and PV in relation to the control sample were observed at $68{ }^{\circ} \mathrm{C}$. No significant differences in AV were observed between the samples containing different antioxidantes. PV values suggested the following order in antioxidant effectiveness: $D T>A P>A A>A C$. However, it should be noted that the use of this index is limited to the early stages of oxidation, in which no significant differences with the control sample were observed (data not shown). The rate of hydroperoxide decomposition increases with temperature and the degree of oxidation, the hydroperoxide concentration reaches a maximum and then decreases at advanced stages of oxidation (Crapiste et al., 1999). TR values showed that DT was the only antioxidant with a protecting effect on the naturally occurring tocopherol. The PC analysis showed the following order in antioxidant effectiveness: DT $>A A>C A$.

Some differences in PV and AV with respect to the control sample were observed at $130^{\circ} \mathrm{C}$. The AV index indicated an antioxidant effect of DT and especially AP at this temperature. PV is not useful to compare treatments because of the high final deterioration. Antioxidant effect can be better assessed by the polar compound analysis when the naturally occurring antioxidants are consumed appreciably and the oil oxidation is in an advanced stage. Under this condition DT and AP showed a protective effect at $130^{\circ} \mathrm{C}(\mathrm{P}<0.05)$.

Ascorbic acid was the best antioxidant in the accelerated Rancimat test, but showed a lower antioxidant activity in storage experiments at $68{ }^{\circ} \mathrm{C}$ and exhibited no effect at $30^{\circ} \mathrm{C}$. This behavior can be attributed to the very low solubility of $A A$ in oils. It has been previously found that AA's protecting efficacy increased when the continuous airflow facilitates emulsification (Velazco et al., 2000). The addition of $\mathrm{AA}$ at $130{ }^{\circ} \mathrm{C}$ augmented the deterioration as measured by both PV and \%PC, while practically the whole naturally occurring tocopherol was consumed. This suggests that AA could deteriorate at high temperatures inhibiting its antioxidant activity.

It can be observed from Table II that the free-fatty-acid and diglyceride contents remained practically constant during all the treatments, indicating no hydrolitic deterioration. Changes in \% $P C$ at $30^{\circ} \mathrm{C}$ were mainly due to the increase of OTG as a result of the oxidation process. Unexpectedly, the concentration of DTG in samples with AP and DT was slightly lower than that obtained for the initial oil. In contrast, an appreciable increment of DTG was observed in samples stored at $68^{\circ} \mathrm{C}$. This result has been previously found, demonstrating that some polymerization also occurs during autoxidation at relatively low temperatures (Crapiste et al, 1999). At high temperatures, oxygen has lower solubility in oils and as a result the autoxidative peroxide formation proceeds at lower rates and becomes gradually replaced with polymerization reactions (Kamal-Eldin and Appelavist. 1996). The distribution of polar

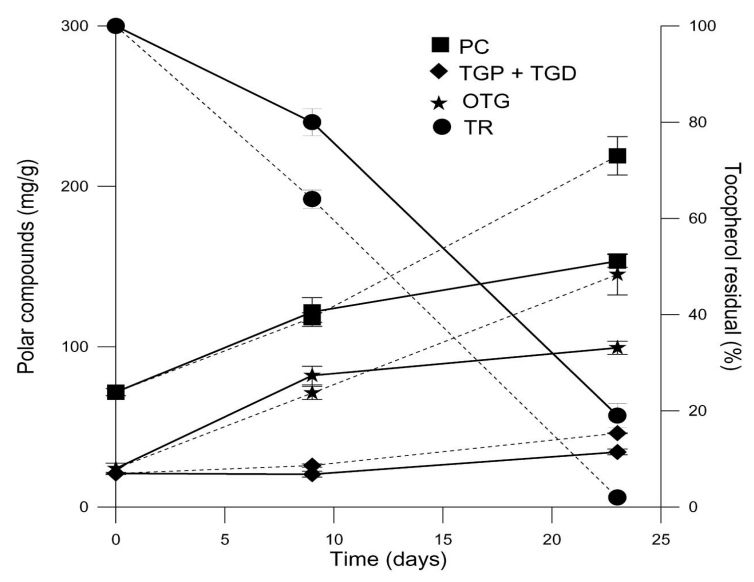

Figure 2

Evolution of polar-compound content and $\alpha$-tocopherol residual at $68^{\circ} \mathrm{C}$

control, ---.---- treated with $100 \mathrm{ppm}$ of $\delta$-tocopherol. Abbreviations: $\mathrm{PC}=$ total polar compounds, TGP $+\mathrm{TGD}=$ total triglyceride polymers, OTG = oxidized triglyceride monomers, $\mathrm{TR}=$ tocopherol residual. 
compounds, with a significant increase in PTG+ DTG, showed that both oxidative and thermal degradation took place during heating at $130^{\circ} \mathrm{C}$.

Figures II and III compare the evolution of polar-compound content between the control and the sample treated with $\delta$-tocopherol at $68^{\circ} \mathrm{C}$ and $130^{\circ} \mathrm{C}$ respectively. The antioxidant effect of DT can be observed, due to the treated oil having lower contents of oxidized triglyceride monomers, especially at the higher times when the oil deterioration is in an advanced stage. From Figure III we can infer that DT also acted as an antipolymerization agent at high temperatures. From the residual naturally occurring tocopherol it can be observed that DT showed some inhibition effect, especially at $68^{\circ} \mathrm{C}$. Under some conditions the tocopherols might be recycled between them, i.e. $\propto$-tocopherol was found to regenerate $\beta$-, $\gamma$ - and $\delta$ tocopherols from their radicals in homogeneous solutions (Kamal-Eldin and Appelqvist, 1996).

In conclusion, this study provides an insight into understanding the behavior of added natural antioxidants on sunflower oil oxidation. While ascorbic acid appears to be a more effective antioxidant according to the OSI method, DT shows better performance when storage experiments are considered. The effectiveness of the different treatments was strongly dependent on temperature and testing methods. Temperature can act in the oxidative process directly by affecting rates of different reactions or indirectly by affecting relative solubility and mass transfer phenomenon of reactants and products. Oxidation experiments are useful to evaluate the effectiveness of antioxidants

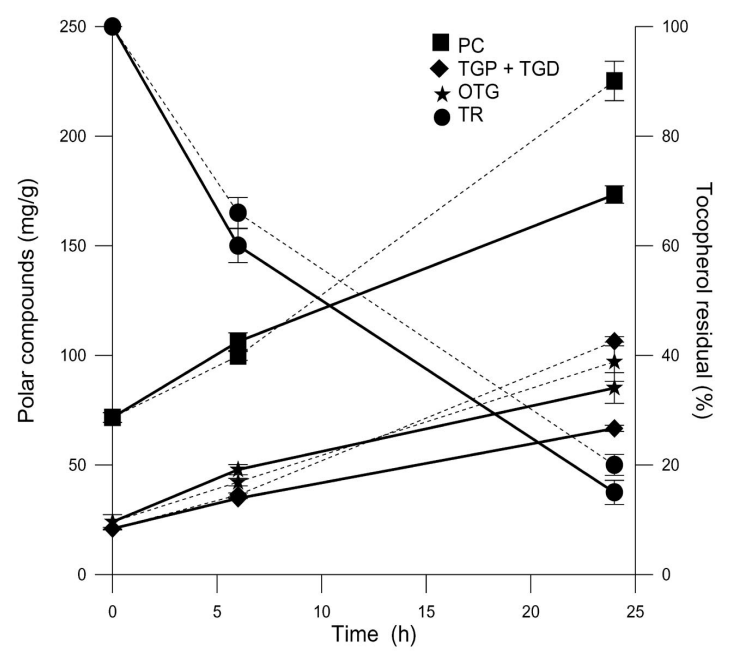

Figure 3

Evolution of polar-compound content and $\alpha$-tocopherol residual at $130^{\circ} \mathrm{C}$

control, ------- treated with $100 \mathrm{ppm}$ of $\delta$-tocopherol. Abbreviations: $\mathrm{PC}=$ total polar compounds, TGP $+\mathrm{TGD}=$ total triglyceride polymers, OTG = oxidized triglyceride monomers, $\mathrm{TR}=$ tocopherol residual. when they are performed under conditions similar to those in which the oil will be used or stored.

\section{ACKNOWLEDGMENTS}

The authors acknowledge the financial support from ANPCyT (Agencia Nacional de Promoción Científica y Tecnológica), CONICET (Consejo Nacional de Investigaciones Científicas y Técnicas) and Universidad Nacional del Sur, Argentina.

\section{REFERENCES}

AOCS 1993. Official Methods and Recommended Practices of the American Oil Chemists' Society, 4th. Ed., D. Firestone (Ed.). The American Oil Chemists Society, Champaign, IL.

Carelli A.A., Bodnariuk P. and Crapiste G.H. 1998. Effectiveness of antioxidants in sunflower oil. In Koseoglu S.S., Rhee K.C. and Wilson R. F. (Ed.) Advances in Oils and Fats, Antioxidants, and Oilseed By-Products, II, 258-261. AOCS Press, Champaign, IL.

Crapiste G.H., Brevedan M.I.V. and Carelli A.A. 1999. Oxidation of sunflower oil during storage. J. Am. Oil Chem. Soc., 76, 1437-1443.

Frankel E.N. 1993. In search of better methods to evaluate natural antioxidants and oxidative stability in food lipids. Trends in Food Science and Technology, 4, 220-225.

Frankel E.N. 1996. Antioxidants in lipid foods and their impact on food quality. Food Chemistry, 57, 51-55.

Frankel E.N. 1998. Lipid Oxidation, The Oily Press, Dundee, 13-77, 129-186.

Giese J. 1996. Antioxidants: tools for preventing lipid oxidation. Food Technology, 50, 73-80.

IUPAC 1992. Standard Methods for the Analysis of Oils, Fats and Derivatives, 7th. Ed., C. Paquot and Hautfenne (Ed.). International Union of Pure and Applied Chemistry, Blackwell Scientific Publications Inc, Oxford.

Jadhav S.J., Nimbalkar S.S., Kulkarni A.D. and Madhavi D.L. 1996. Lipid oxidation in biological and food systems. In Madhavi D.L., Deshpande S.S. and Salunkhe D.K. (Ed.). Food Antioxidants: Technological, Toxicological, and Health Perspectives, 5-63. Marcel Dekker Inc., New York.

Kamal-Eldin A. and Appelqvist L.Å. 1996. The chemistry and antioxidant properties of tocopherols and tocotrienols. Lipids, 31, 671-701.

Márquez-Ruiz G., Jorge N., Martín-Polvillo M. and Dobarganes M.C. 1996. Rapid, quantitative determination of polar compounds in fats and oils by solid-phase extraction and size-exclusion chromatography using monostearin as internal standard. J. Chromatog., 479, 55-60.

Márquez-Ruiz G. and Dobarganes M.C. 1997. Analysis of lipid oxidation products by combination of chromatographic techniques. In McDonald R.E. and Mossoba M.M. (Ed.). New Techniques and Applications in Lipid Analysis, 217-233. AOCS Press, Champaign, IL.

Márquez-Ruiz G., Velasco J. and Dobarganes C. 2000. Evaluation of oxidation in dried microencapsulated fish oils by a combination of adsorption and size exclusion chromatography. Eur. Food Res. Technol., 211,13-18.

Niki E. 1996. $\alpha$-Tocopherol. In Cadenas E. (Ed.). Handbook of Antioxidants, 3-25, Marcel Dekker Inc., New York. 
St. Angelo A.J. 1996. Lipid oxidation in foods, CRC Crit. Rev. Food Sci. Nutr., 36,175-224.

Velazco J., Dobarganes M.C. and Márquez-Ruiz. 2000. Application of the accelerated test Rancimat to evaluate oxidative stability of dried microencapsulated oils. Grasas y Aceites, 51(4), 261-267.

White P.J. and Xing Y. 1997. Antioxidants from cereals and legumes. In Shahidi F. (Ed.) Natural Antioxidants: Chemistry, Health Effects, and Applications, 224-244, AOCS Press, Champaign, IL.

Yanishlieva N.V. and Marinova E.M. 1992. Inhibited oxidation of lipids. I: complex estimation and comparison of the antioxidative properties of some natural and synthetic antioxidants. Fat Sci. Technol., 94, 374-379.
Yanishlieva N.V. and Marinova E.M. 2001. Stabilisation of edible oils with natural antioxidants. Eur. J. Lipid Sci. Technol., 103, 752-767.

Yanishlieva N.V., Kamal-Eldin A., Marinova E.M. and Toneva A.G. 2002. Kinetics of antioxidant action of $\alpha$ and $\gamma$-tocopherols in sunflower and soybean triacylglycerols. Eur. J. Lipid Sci. Technol., 104, 262-270. 